\title{
Relationship between Pilates practice time and the electromyographic response of pelvic floor muscles in climacteric women: An observational study
}

\author{
Relação entre o tempo de prática de Pilates e a resposta eletromiográfica dos múscullos do assoallho \\ pélvico em mulheres climatéricas: Um estudo observacional
}

Relación entre el tiempo de práctica de Pilates y la respuesta electromiográfica de los músculos del suelo pélvico en mujeres climatéricas: Un estudio observacional

Received: 03/24/2021 | Reviewed: 03/30/2021 | Accept: 04/01/2021 | Published: 04/12/2021

\author{
Alethéa Cury \\ ORCID: https://orcid.org/0000-0001-9421-3864 \\ Federal University of Rio Grande do Norte, Brazil \\ E-mail: alethea.cury@gmail.com \\ Vanessa Patrícia Soares de Sousa \\ ORCID: https://orcid.org/0000-0003-4117-3859 \\ Federal University of Rio Grande do Norte, Brazil \\ E-mail: vanessa.sousa@ufrn.br \\ Laiane dos Santos Eufrásio \\ ORCID: https://orcid.org/0000-0003-0578-7140 \\ Federal University of Rio Grande do Norte, Brazil \\ E-mail: laieufrasio@hotmail.com \\ Elizabel Ramalho Viana \\ ORCID: https://orcid.org/0000-0002-2692-9251 \\ Federal University of Rio Grande do Norte, Brazil \\ E-mail: elizabelviana@gmail.com
}

\begin{abstract}
Ojective: To analyze the relationship between practice time in the Pilates method and the electromyographic response of the pelvic floor muscles (PFM) in climacteric women. Design: An observational study. Participants: Twenty-eight (28) climacteric women with a mean age of $53.97( \pm 6.11)$ years and a minimum period of 6 months of practicing the Pilates Method. Main Outcome Measures: An evaluation sheet containing sociodemographic, obstetric and gynecological data. Electromyographic capture of PFM by surface electromyography (Miotool Uro 200, Miotec ${ }^{\circledR}$, Brazil). Results: The results showed that the electromyographic data (base tone, maximum voluntary contraction, sustained contraction) did not show statistical correlation between the data $(r>-0.057 ; p>0.63)$. Conclusions: The Pilates Method does not seem to influence the electromyographic response of PFM. The findings suggest that this cannot be considered a specific activity for training the pelvic floor muscles.
\end{abstract}

Key words: Climateric; Biofeedback; Pelvic floor.

\section{Resumo}

Objetivo: Analisar a relação entre o tempo de prática no método Pilates e a resposta eletromiográfica dos músculos do assoalho pélvico (MAP) em mulheres climatéricas. Design: Estudo observacional. Participantes: Vinte e oito mulheres climatéricas, com média de idade 53,97 $( \pm 6,11)$ anos e tempo mínimo de 6 meses de prática do Método Pilates. Metodologia: Ficha de avaliação contendo dados sociodemográficos, obstétricos e ginecológicos. Avaliação funcional do assoalho pélvico (AFA) pela palpação bidigital. Captação eletromiográfica dos MAP por eletromiógrafo de superfície (Miotool Uro 200, Miotec ${ }^{\circledR}$, Brasil). Resultados: Os resultados demonstraram que os dados eletromiográficos (tônus de base, contração voluntária máxima, contração resistida) dos MAP não apresentaram correlação estatística à média do tempo praticado ( $\mathrm{r}>-0,057 ; \mathrm{p}>0,63)$. Conclusões: O Método Pilates parece não influenciar na ativação eletromiográfica dos MAP. Os achados sugerem que este não pode ser considerado uma atividade específica para o treinamento dos músculos do assoalho pélvico.

Palavras-chave: Climatério; Biorretroalimentação; Diafragma da pelve.

\section{Resumen}

Objetivo: Analizar la relación entre el tiempo de práctica en el método Pilates y la respuesta electromiográfica de la musculatura del suelo pélvico (MAP) en mujeres climatéricas. Diseño: Estudio observacional. Participantes: Veintiocho mujeres climatéricas, con una edad promedio de 53,97 $( \pm 6,11)$ años y un período mínimo de 6 meses de práctica del Método Pilates. Metodología: Ficha de evaluación con datos sociodemográficos, obstétricos y 
ginecológicos. Evaluación funcional del suelo pélvico (AFA) mediante palpación bidigital. Captura electromiográfica de MAP mediante electromiografía de superficie (Miotool Uro 200, Miotec $®$, Brasil). Resultados: Los resultados mostraron que los datos electromiográficos (tono basal, contracción voluntaria máxima, contracción resistida) del MAP no mostraron correlación estadística con el tiempo promedio practicado ( $r>-0.057$; p>0.63). Conclusiones: El Método Pilates no parece influir en la activación electromiográfica de MAP. Los hallazgos sugieren que esto no puede considerarse una actividad específica para entrenar los músculos del suelo pélvico.

Palabras clave: Climaterio; Biorretroalimentación; Diafragma de la pelvis.

\section{Introduction}

The effectiveness of the Pilates Method (PM) presents scientific evidence on flexibility, muscle strength, postural alignment and dynamic and static balance (Engers et al., 2016). However, studies are needed to assess the timing of the pelvic floor muscles (PFM) contractions, the forms of contraction, activity and the relationship between PFM and other structures during impact activities in women need further studies (Radlinger et. al., 2018; Sipilä et. al., 2020)

Recently, a study involving climacteric women stated that the more active these women are, the better the functionality of their pelvic floor (Varela et al., 2018). It is known that women who are in the climacteric period physiologically have a progressive hormonal deficiency (hypoestrogenism) which can directly affect the musculature of the PFM, causing weakness in it (Çeliker et. al., 2015). Associated with this, the type of physical activity they perform may have a direct influence on the pelvic floor muscle function (Golçalvez, Fernandez \& Souza, 2018). The literature shows that high impact and high intensity physical activities favor occurrences of kinetic-functional dysfunctions of PFM, while other activities do not have this negative impact (Szumilewicz et. al., 2019).

A study by Sipilä et. al. (2020) analyzed the effects os physical activity on 1393 women (aged 47-55 years) at different stages of menopausal women. Theya observed an improvement in the skeletal muscle system, mobility and a lower risk of fractures. Furthermore, exercises based on the Pilates Method (PM) require activation of the muscular complex called Powerhouse in order to be performed correctly, which is composed of the hip-pelvic-lumbar joint (Marés, 2012). The pelvic floor muscles are anatomically interconnected with the abdominal wall, respiratory diaphragm and lumbar spine (Lemos et al., 2019). Thus, due to the mechanism of muscle synergism during stabilization exercises, neuromuscular activation occurs between abdominal and paravertebral muscles, and consequently activate PFM. In exercises which demand increased intra-abdominal pressure, the recruitment of PFM fibers tends to be greater (Spasford \& Hodges, 2001) in order to avoid fecal and urinary incontinence. However, scholars question the effectiveness of joint contraction with the transverse abdomen muscle as a result of strengthening PFM (Bø K. et. al., 2013).

Electromyography (EMG) is a way of assessing muscle activity and provides information about the behavior of muscle fibers during exercise or rest (Dias et. al., 2014). Electromyographic evaluation of the pelvic floor is performed by intracavitary probes with metallic sensors, which capture deep and superficial muscle activation (Bertotto, 2016).

In this context, the question which guided this study was: can the time of PM practice influence the electromyographic response of PFM in climacteric women? To the best of our knowledge, this is the first study which compares the muscle behavior of PFM in climacteric women through electromyography in relation to their practice time of the Pilates Method.

\section{Methodology}

\section{Study design and setting}

This is an observational study that according to Fletcher and Fletcher (2006) consists of the possibility of describing and identifying behaviors that can be categorized, revealing details of the person-environment interaction This observational study was conducted following the guidelines of the Strengthening the Reporting of Observational Studies in Epidemiology 
(STROBE). Data from this cross-sectional study were collected between January and August 2016 at the Physiotherapy Laboratory in women's health (Lafism/UFRN) at the University of Rio Grande do Norte (UFRN).

\section{Participants}

A total of 28 climacteric women aged between 45 and 65 years who have been practicing Pilates for at least 6 months were evaluated. The sampling process was non-probabilistic. Inclusion criteria were: (a) not having undergone urogynecological surgery, such as surgery for pelvic organ prolapse, correction of urinary or fecal incontinence; (b) not reporting the presence of vaginal and/or urinary infection; (c) no diagnosis of pelvic floor dysfunction. Exclusion criteria were: (a) inability to understand verbal commands related to PFM contraction during the evaluation; (b) presenting pelvic organ prolapse at levels 3 and 4; and (c) refusal to participate in any research procedure. All participants signed an informed consent form to participate in the study. This research was approved by the Research Ethics Committee of the Federal University of Rio Grande do Norte under number $1,529,531$, according to resolution $466 / 12$ of the National Health Council.

\section{Sample calculation}

The Pearson Test scale was used, in which the effect size (ES) represents: 0.10 - small, 0.30 - medium, and 0.50 - large (alpha: 0.05). The sample size was calculated considering a sampling error of $10 \%$, a $95 \%$ confidence interval and homogeneous distribution. The study power reached $86 \%: 28$ women.

\section{Procedure and equipment}

The patients initially answered an evaluation form containing questions about sociodemographic, obstetric and gynecological data. Next, electromyographic capture was performed using Miotec ${ }^{\circledR}$ electromyography equipment (Biomedical Equipment Ltda., Miotool 200 model, two channels), 14-bit resolution analog/digital converter (A/D), internal gain of 1000 times, sampling frequency of $2000 \mathrm{~Hz}$, and common mode rejection (CMRR) of $110 \mathrm{~dB}$. The electromyographic signal of the PFM was captured using an endovaginal probe. A water-based, non-greasy, transparent and odorless lubricating gel was used to introduce the probe into the vaginal canal to prevent allergies. The reference electrode (Chatanooga ${ }^{\circledR}$ ) was attached to the lateral malleolus of the left ankle.

The protocol for electromyographic evaluation was performed using the software installed on the Miotool ${ }^{\circledR}$ device, obtaining three variables: (1) base tone (BT), (2) maximum voluntary contraction (MVC), and (3) sustained contraction (R), expressed in $\mu \mathrm{v}$.

The volunteer was asked to stay in the lithotomy position and the intracavitary electrode was introduced into the vaginal canal to collect the BT data. Next, the woman was asked to keep the pelvic floor muscle (PFM) relaxed for 30 seconds for electromyographic capture. The data for the the maximum voluntary contraction (MVC) were expressed by the average of 3 strong PFM contractions in the interval of 10 seconds. The sustained contraction data (R) was collected requesting a sustained contraction of up to 10 seconds. A rest time of 30 seconds was respected between the three electromyographic capture stages.

\section{Data processing and statistical analysis}

The electromyographic data were processed using Biotrainer Uro 2008 software (Miotec ${ }^{\circledR}$ Equipamentos Biomédicos Ltda., Brazil). Statistical analysis was performed using the Statistical Package for Social Sciences (SPSS), version 20.00. Descriptive statistics are presented through the values of means and standard deviation of the analyzed variables, as well as through absolute and relative frequencies. The Shapiro-Wilk test was used to test the distribution of quantitative variables for inferential analysis. Spearman's correlation test was used to analyze the relationship between Pilates practice time (in months) 
and the electromyographic activation variables of the pelvic floor (BT, MVC and R, in microvolts). The significance level adopted in all tests was $\mathrm{p}<0.05$.

\section{Results}

The characteristics of group are shown in Table 1.

Table 1 - Sociodemographic, obstetric, gynecological and anthropometric characterization of the sample ( $\mathrm{n}=28)$.

\begin{tabular}{|c|c|}
\hline Sociodemographic data & $\mathrm{n}=28$ \\
\hline Age (years) & $54,14 \pm 6,14$ \\
\hline \multicolumn{2}{|l|}{ Civil Status } \\
\hline Have companion & $60,7 \%(17)$ \\
\hline Without companion & $39,3 \%(11)$ \\
\hline \multicolumn{2}{|l|}{ Gynecological data } \\
\hline Number of birth & $1,75 \pm 1,10$ \\
\hline \multicolumn{2}{|l|}{ Birth path } \\
\hline Cesarea & $25 \%$ \\
\hline Vaginal & $58 \%$ \\
\hline Whithout children & $17 \%$ \\
\hline \multicolumn{2}{|c|}{ Anthropometric data and } \\
\hline \multicolumn{2}{|l|}{ Pilates time } \\
\hline Weight $_{(\mathrm{Kg})}$ & $62,02 \pm 8,64$ \\
\hline Height $_{(\mathrm{m})}$ & $1,59 \pm 0,05$ \\
\hline $\mathrm{BMI}_{(\mathrm{Kg} / \mathrm{m} 2)}$ & $24,26 \pm 2,84$ \\
\hline WHR ratio & $0,78 \pm 0,07$ \\
\hline Pilates time (months) & $48,46 \pm 34,79$ \\
\hline
\end{tabular}

Legend: BMI, body mass index; WHR, waist-to-hip ratio. Note: Quantitative variables are presented as mean \pm standard deviation. Categorical variables are presented in percentages. Source: Research data.

The Table 2 shows the results of relationship between Pilates practice time and the electromyographic response of pelvic floor muscles. There was no statistically significant difference $(\mathrm{p} \geq 0.05)$ in amplitude of muscle activation and the time of practice of the Pilates Method (months). 
Table 2 - Relationship between electromyographic activity of the pelvic floor muscles and the time of practice of the Pilates method.

\begin{tabular}{cccc}
\hline $\begin{array}{c}\text { Independent } \\
\text { variable }\end{array}$ & $\begin{array}{c}\text { Dependent } \\
\text { variable }\end{array}$ & $\mathrm{r}$ & $\mathrm{p}$ \\
\hline $\begin{array}{c}\text { Time of } \\
\text { practice of the }\end{array}$ & $\mathrm{TB}(\mu \mathrm{V})$ & 0,050 & 0,80 \\
$\begin{array}{c}\text { Pilates method } \\
\text { (months) }\end{array}$ & $\mathrm{CVM}_{(\mu \mathrm{V})}$ & - & \\
& $\mathrm{R}_{(\mu \mathrm{V})}$ & 0,094 & 0,77
\end{tabular}

Note. TB: base tone; CVM: maximum voluntary contraction; A: resistance. Significance level p <0.05 generated by Spearman's correlation test. Source: research data

\section{Discussion}

This study demonstrated that there was no relationship between the electromyographic variables (base tone, maximum voluntary contraction and resisted contraction) of the pelvic floor muscles and the practicing time of the Pilates Method in climacteric women.

Although there was no influence of the PM practice time on PFM, a recent study (Varela et. al, 2018) with active climacteric women suggested a positive correlation between physical activity and PFM function. The difference in these findings can be attributed to two factors: the type of equipment used in evaluating the PFM and type of exercise practiced by the sample. The present study evaluated PFM using surface EMG and specified the type of physical activity (Pilates), while the other study evaluated PFM using perineometry and did not distinguish the type of physical activity. Regarding the PFM assessment, the equipment differs in the way of interpreting the data; while perineometry captures internal pressure triggered by the contraction of the PFM and may also influence the intra-abdominal pressure, EMG analyzes the capture of electrical signals resulting from muscle depolarization in the capture site, and may or may not have interference from synergistic muscles. In addition to these aspects, the lack of specifying the type of exercise may differ in the muscular responses of the PFM.

A study by Ferla et. al. (2016) compared two groups of young women (20 to 40 years old), sedentary and those who performed PM, and found no difference between groups in the PFM assessment. Dias (2014) found no difference in the effectiveness of PM in the function of pelvic floor contractility in primiparous pregnant women. This fact seems to indicate that regardless of the sample characteristics, the PM does not influence PFM functionality when evaluated by perineometry.

The study also showed that the analyzed sample had experienced a high occurrence of vaginal delivery, which may have influenced the main findings. It is known that vaginal delivery can cause temporary or permanent damage to the pelvic floor (De Tayrac \& Letouzey, 2016). A study conducted by Weidner et al. (2006) showed changes in the electromyographic patterns of the levator ani muscle in women who had undergone this type of delivery. The origin of these changes is mechanical and ischemic, and results in muscle and nerve changes (Callewaert et. al., 2015).

The present study hypothesized that due to the longtime of practicing the PM, the abdominopelvic synergy would be more active in women who had been exercising for a longer time, and thus the EMG data would present a correlation between the variables. The pelvic floor muscles are apparently not specifically requested during PM exercises, only being an integral part of the hip-pelvic-lumbar complex, called Powerhouse (Marés, 2012)

Dynamic understanding of the muscle behavior mechanism of PFM during PM exercises is a gap in the literature. Studies recommend that performing intentional co-contraction of PFM during exercises which increase intra-abdominal pressure can prevent leakage of urine and feces, and thus strengthen the pelvic muscles (Bø, 2012). However, 30\% of women do not know 
how to contract effectively or have difficulty voluntarily contracting PFM (Ribeiro \& Ankier, 2012). This inefficiency was identified in this study, as most of the volunteers did not have knowledge about the location of the PFM, nor did they know how to perform the isolated contraction of this musculature when the muscle contraction was requested in the initial evaluation. According to Bø and Sherburn (2005), the most common mistake that women have is in joint contraction with accessory muscles such as their glutes, adductors and abdominals. Thus, for training purposes it is essential to teach the correct contraction of the PFM and evaluate the muscle strength measurement before and after any intervention to compare the results.

The Pilates Method currently seeks new proposals and changes in this theme. The literature has demonstrated the importance of breathing exercises and the conscious contraction of PFM during programs based on the PM, and not only due to the consequence of synergistic contraction as previously assumed. In addition, findings in a recent systematic review show that the practice of the Pilates method can influence balance, posture, sleep, anxiety and depression, fatigue and respiratory function in women post menopause (Oliveira, 2020). Korelo (2012) suggests that adding a voluntary PFM contraction to a Pilates exercise program is more effective than performing the method alone in improving the strength of the pelvic floor muscles in sedentary nulliparous women.

Bertotto et al. (2016) conducted a randomized controlled study with 49 postmenopausal women and concluded that the increase in strength and electromyographic activity was effective in specific muscle strength training for PFM. Thus, it is believed that there may be a gap in the practical aspect in the PM classes, either due to a lack of muscular awareness by practitioners in properly contracting the PFM, or due to the absence of specific verbal command by the professionals to perform contraction of this musculature while performing the exercises. Thus, the present study proposes a correct reflection of this theme to instructors and practitioners of the Pilates Method, and which is still little explored in the literature.

One of the limitations of the study was to not limit the maximum time for practicing the chosen activity. Although a minimum time has been recommended, it is important to note that a prolonged period of physical activity promotes less significant muscle adaptations than at the beginning, considering that systematic adaptations to the initial exercise have an agreed period. Some women in this study had more than three times the practice time than others. Another limitation was in relation to the different exercise protocols that the PM offers because the practitioners had different levels of training, which can influence the findings. Therefore, the results of this study cannot be generalized to the general population.

\section{Conclusion}

The findings of this study indicate that there is no relationship between the electromyographic activity of the pelvic floor muscles and the practice time of the Pilates Method in climacteric women. Thus, the PM did not prove to be a specific activity for training the PFM.

As a suggestion for future work, we recommend conducting a new observational study in young women in order to compare the data of the current research. In addition, it is recommended to carry out follow-up, with pre and post evaluation of the studied sample.

\section{References}

Bertotto (2016). A Randomized controlled clinical trial pelvic floor training techiques with and whithout electromyographic biofeedback in postmenopausal women with stress urinary incontinence. Dissertação [Mestrado em Ciências Médicas] - Universidade Federal do Rio Grande do Sul, 78p.

B $\varnothing, \mathrm{K} .$, ;\& Helbert, R. (2013) There is not yet strong evidence that exercise regimens other than pelvic floor muscle training can reduce stress urinary incontinence in women: a systematic review. J Physiother, 59(3), 159-168. 10.1016/S1836-9553(13)70180-2.

Bø, K., Morkved, S., Frawley, K., \& Sherburn, M. (2012). Evidence for benefit of transversus abdominis training alone or in combination with pelvic floor muscle training to treat female urinary incontinence: a systematic review. NeurourolUrodyn,. 28(5), 368-373. 10.1002/nau.20700

Bø, k. S. M. (2005). Evaluation of female pelvic-floor muscle function and strength. Physical Therapy. Physical Therapy 85(3), 269-282. 10.1093/ptj/85.3.269 
Callewaert, G., Albersen, M., Janssen, K., Damaser, M. V., \& Depresta, D. V. (2015). The impact of vaginal delivery on pelvic floor function - delivery as a time point for secondary prevention Royal College of Obstetricians and Gynaecologists, 123(5), 678-681. 10.1111/1471-0528.13505

Çeliker, T. O., Kaya, M. E., Gökhan, T., Mete, E. A., Özgur, Y. A., Mehtap, M., Niyazi, A., \& İsmail Mete, II. (2015). Do stages of menopause affect the outcomes of pelvic floor muscle training? Menopause., 22(2), 175-184. 10.1097/GME.0000000000000278.

De Tayrac R, \& Letouzey V. (2016). Métodos de empurrar durante o parto vaginal e o assoalho pélvico e os resultados perineais: uma revisão. Curr Opin Obstet Gynecol, $28(6), 470-476$.

Dias, J. M., Menacho, M. O., Mazuquin, B. F., Obara, K., Mostagi, F. Q. R. C., Lima, T. B., Moura, F. A., Abrão, T., Iversen, M. D., \& Cardoso, J. R. (2014). Comparison of the electromyographyc activity of the anterior trunk during the execution of two Pilates exercises - teaser and longspine - for healthy people. $J$ electromyogr kinesiol., 24(5), 689-697. 10.1016/j.jelekin.2014.06.005.

Engers, P. B., Rombaldi, A. J., Portella, E. G., \& Silva, M. C. (2016). Efeitos da prática do método Pilates em idosos: uma revisão sistemática. Rev bras reumatol., 56(4), 352-365. http://dx.doi.org/10.1016/j.rbr.2015.11.003

Ferla, L., Darski, C., Paiva, L. L., Sbruzzi, G., \& Vieira, A. (2016). Synergism between abdominal and pelvic floor muscles in healthy women: a systematic review of observational studies. Fisioter. Mov.; 29(2), 399-410. http://dx.doi.org.10.1590/0103-5150.029.002.AO19

Fletcher, R. H.; \& Fletcher, S. W. Epidemiologia clínica: elementos essenciais. (4a ed.), Artes Médicas, 2006.

Gonçalves, M. L. C., Fernandes, S., \& Sousa, J. B. (2018). Do moderate aerobic exercise and strength training influence electromyographic biofeedback of the pelvic floor muscles in female non-athletes? J Phys Ther Sci.; 30(2),313-319. 10.1589/jpts.30.313.

Korelo, R. I. G., Kosiba, C. R., Grecco, L., \& Matos, R. A. (2012). The abdominal strengthen influence in perineal function when associated, or not, to the orientation of the pelvic floor contraction, in nulliparous. Fisioter. Mov. 24 (1), 75-85. https://doi.org/10.1590/S0103-51502011000100009

Sipilä, S., Törmäkangas, T., Sillanpää, E., Aukee, P., Kujala, U., Kovanen, V., \& Laakkonen, E. K. (2020). Muscle and bone mass in middle-aged women: role of menopausal status and physical activity, Journal of Cachexia, Sarcopenia and Muscle, 11, 698-709. https://doi.org/10.1002/jcsm.12547.

Lemos, A. Q., Brasil, C. A., Valverde, D., Ferreira, J. D. S., Lordêlo, P., \& Sá, K. N. (2019). The pilates method in the function of pelvic floor muscles: Systematic review and meta-analysis. J Bodyw Mov Ther. 23(2):270-277. 10.1016/j.jbmt.2018.07.002.

Marés, C. (2012). The importance of central stabilization in Pilates method: a systematic review. Fisioter. Mov.; 25(2), 445-451. https://doi.org/10.1590/S010351502012000200022

Oliveira, M. M., Clementino, A. P. G., \& Oliveira, E. A. (2020). Benefits of the Pilates method for postmenopausal women: systematic review. Research, Society and Development, $9(7), 1-13$

Radlinger, L., Baeyen, J-P., Leitner, M., \& Moser, H. (2018). Pelvic floor muscle activity during impact activities in continente and incontinent women: a systematic review. Int Urogynecol J, 29, 179-196. 10.1007/s00192-017-3441-1

Ribeiro, A. T. A., \& Ankier, C.(2012). A relação do grau de força muscular do assoalho pélvico com a satisfação sexual feminina. Revista latinoamericana de medicina sexual - ReLAMS... 1(1), 14-22.

Sapsford, R. R., Hodges, P. W., Richardson, C. A., Cooper, D. H., Markwell, S. J., \& Jull, G. A. (2001).Co-activation of the abdominal and pelvic floor muscles during voluntary exercises. Neurourol Urodyn, 20(1), 31-42. 10.1002/1520-6777(2001)20:1<31::aid-nau5>3.0.co;2-p

Szumilewicz, A., Dornowski, M., Piernicka, M., Worsk, A., Kuchta, A., Radzimiński, L., \& Jastrzębski, Z. (2019).High-Low Impact Exercise Program Including Pelvic Floor Muscle Exercises Improves Pelvic Floor Muscle Function in Healthy Pregnant Women - A Randomized Control Trial. Physiol., 30 , 1-11. https://doi.org/10.3389/fphys.2018.01867.

Varella, L. R. D., Angelo, P. H., De Oliveira, M. C. E., Bezerra, L. O., De Melo, R. T., \& Micussi, M. T. A. B. C. (2018).Physical activity and pelvic floor muscles function in climacteric women: a transversal study. ConScientiae Saúde.; 17(3),239-247. 10.5585/ConsSaude.v17n3.8011

Weidner, A. C., Jamison, M. G., Branham, V., Soutrh, M. M., Borawki, K. M., \& Romero, A. A. (2006). Neuropathic injury to the levator ani occurs in 1 in 4 primiparous women. Am J Obstet Gycelol., 195(6), 1851-6. 10.1097/00132582-200706000-00027 